\title{
Earthquake in southern Sweden wakes up Denmark on 16 December 2008
}

\author{
Peter H.Voss, Tine B. Larsen, Lars Ottemöller and Søren Gregersen
}

A moderately strong earthquake struck southern Sweden $5 \mathrm{~km}$ south-west of the town of Sjöbo, $60 \mathrm{~km}$ east of Malmö, in the early morning at 6:20 a.m. local time on 16 December 2008. The epicentre was located in Skåne, a region that is known for its extremely low seismicity, and its location was determined to be $55.5^{\circ} \mathrm{N}$ and $13.6^{\circ} \mathrm{E}$ with an uncertainty of about $6 \mathrm{~km}$. A depth of $9 \mathrm{~km}$ with an uncertainty of $3 \mathrm{~km}$ was obtained from teleseismic observations at the Yellowknife seismic array, USA. Since waveform data from the Swedish national seismic network are not yet available, depth estimation using local stations has so far not been attempted. During the period 1970-2008, only three small earthquakes were detected in the region; the largest measured 2.8 on the local Richter scale. To our knowledge none of these previous earthquakes were felt by people. The historical archives dating back to 1375 show that 14 other earthquakes have been felt in the area. The largest of these, recorded in 1894, was felt over an area of $7300 \mathrm{~km}^{2}$ and had an epicentre $50 \mathrm{~km}$ east of the 16 December 2008 earthquake (Scandinavian Earthquake Archive 2003). The activity in southern Sweden is similar to that of northern Sjælland and north-western Jylland, and confirms the low seismicity of the region (Gregersen et al. 1991).
Even though the earthquake was unusual, the event was not totally unexpected. Northern Europe is under constant pressure from the mid-Atlantic Ridge, and the resulting stress is released in small to moderate size earthquakes. The local stress field is further modified by postglacial rebound. Earthquakes in Denmark and southern Sweden occur where there are weaknesses or faults in the subsurface. In some cases the earthquakes occur where there are no mapped faults (Gregersen et al. 1996).

Shaking from the earthquake was felt widely in Denmark. Strong shaking and low-frequency earthquake sounds frightened many people and caused them to abruptly leave their houses. Authorities such as the police and the Geological Survey of Denmark and Greenland (GEUS) were flooded with phone calls and e-mails from concerned citizens. Fortunately the earthquake did not cause any real damage, and no one was in danger at any time.

\section{Macroseismic effects in Denmark}

The basic physical earthquake parameters are determined from instrumental recordings. However, the effects of the earthquake on people, buildings, and nature require human inter-
Fig. 1. Map showing the epicentre of the 16 December 2008 earthquake (yellow circle) and the locations of the first 3000 macroseismic reports received (red circles) from Denmark. Known faults are also shown.

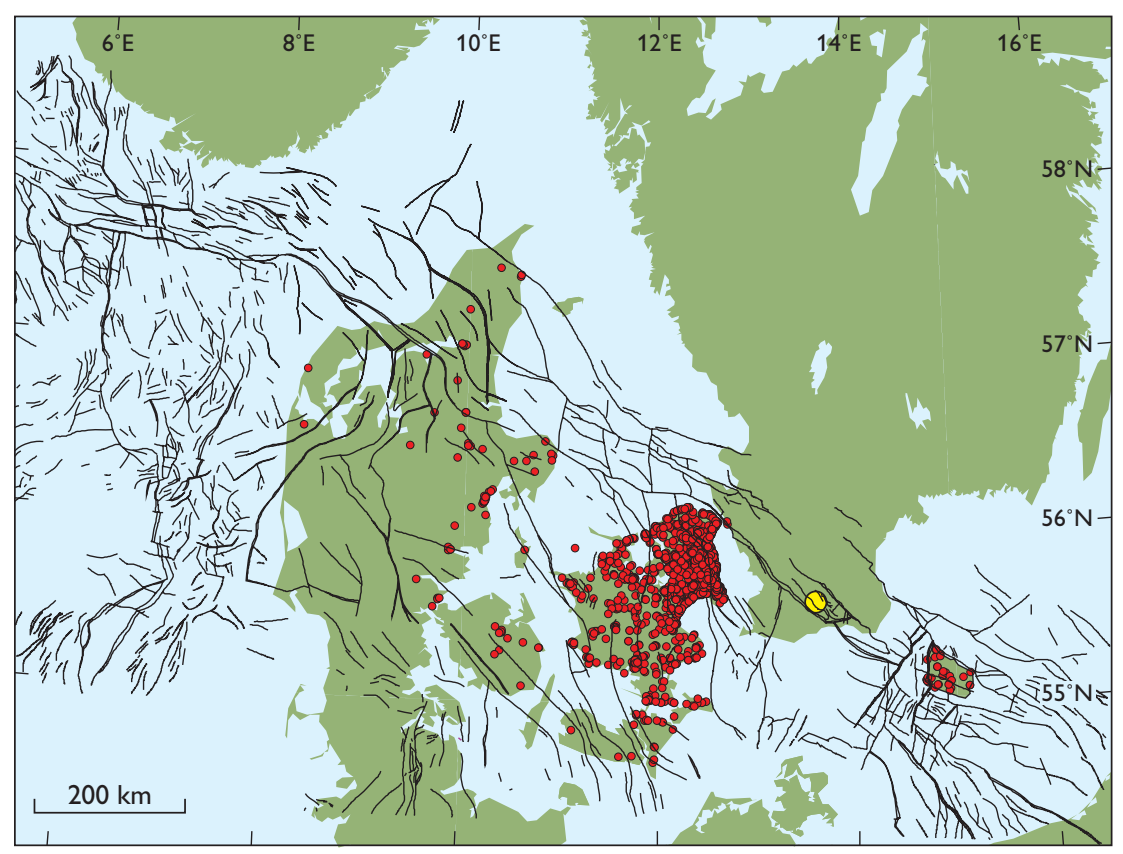




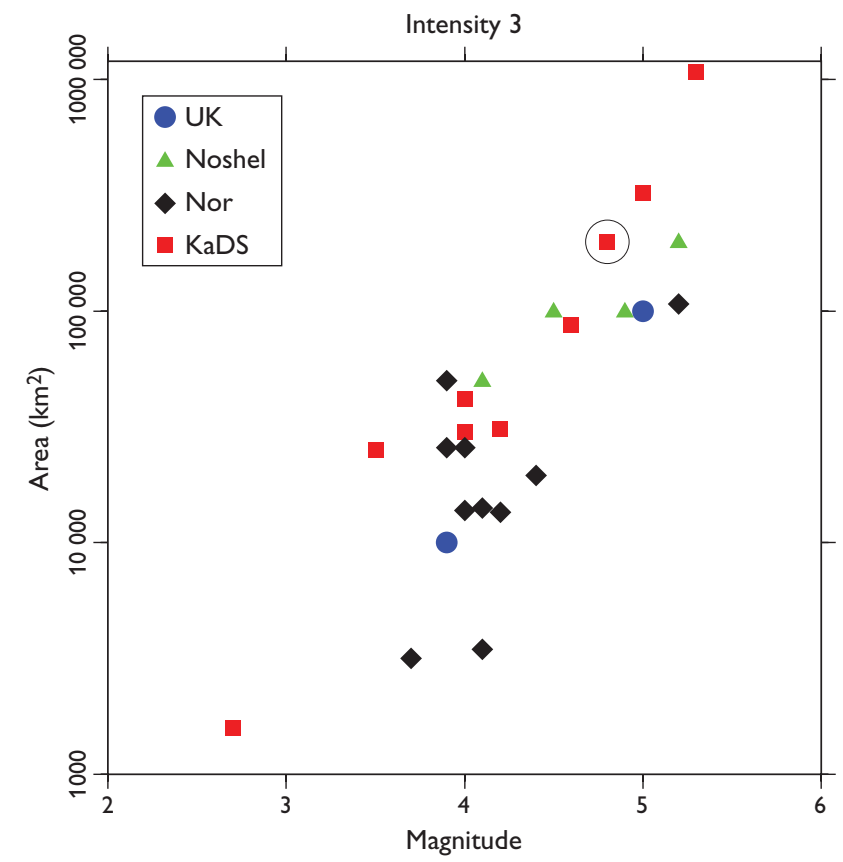

Fig. 2. Perceptibility areas for 25 selected earthquakes (area of intensity 3) correlated with their magnitudes. The red squares are for the shield region in Kaliningrad, Denmark and Sweden (KaDS) compared to the 16 December 2008 earthquake. These areas are larger than those in Norway (NOR), on the Norwegian continental shelf (Noshel) and in the United Kingdom (UK). The 16 December earthquake (preliminary result shown by a circle) seems to confirm the trend.

action to be delineated. Immediately following the earthquake, GEUS requested input from the public through the news media and our own web page. Our earthquake questionnaire was placed on www.geus.dk and a paper copy was mailed to those who had no internet access or who felt uncomfortable about reporting electronically. After a few days, GEUS had received more than 3000 earthquake reports (Fig. 1), and after a month the number exceeded 4000 reports. This is a large increase compared to the last widely felt earthquake in Denmark in 2001, where we received little more than 400 reports (Larsen et al. 2008) and the one in 1985 in Kattegat, which was almost as large as the 16 December 2008 earthquake, where we received a total of around 500 reports from Sweden and Denmark.

In Denmark alone the area where the earthquake was felt covers about $50000 \mathrm{~km}^{2}$ (Fig. 1). Earthquakes in Scandinavia are felt over much larger areas than in California, where C.F. Richter worked when he invented the Richter magnitude scale. Thus the attenuation in Scandinavia is lower than that in California. A comparison of local observations of 25 earthquakes in different regions and their magnitude suggests that the affected area this time will exceed $100000 \mathrm{~km}^{2}$ (Fig. 2).

Reports from the population are an important tool to assess the impact of an earthquake and to identify locations that are particularly vulnerable to ground shaking. This is still of great interest as earthquakes can be compared to historic events predating the era of instrumental recording. This information is used in seismic hazard studies, for example in connection with large construction projects. The GEUS questionnaire comprises the address of the observer, information about the building in which the observer was located and detailed information about shaking and other effects caused by the earthquake. Shaking is strongly amplified in tall buildings, and the European macroseismic scale (Grünthal et al. 1998) recommends that shaking observations above the 5 th floor are not taken into account when determining the intensity of an earthquake. A detailed study of the 4000 current reports has not yet been completed, but the reports will provide valuable shake information especially for Sjælland.

In many locations the earthquake was felt strongly. Some examples, with locations shown on Fig. 3, are: Copenhagen: "walls, closet and bed were shaking", Gilleleje: "the chair I was sitting in was shaking", Humlebæk: "it was as if the bed was shaken - it felt very terrifying", Ålborg: "it felt as if someone was shaking my bed gently", Kettinge: "as when a large truck is just outside".

Some reports claim that the earthquake caused a road in Helsingør to crack. Inspection of the road confirms the presence of cracks, but it is not obvious that the cracks opened during the earthquake. New asphalt was added to the road a year earlier, and the small cracks are located in the weak zone where new asphalt overlaps with old. The road is exposed to heavy traffic and the cracks could have opened at any time. They do not look any different from other asphalt cracks. The European-Mediterranean Seismological Centre has also received information (a photo) of cracked asphalt in Sweden, but it has not been confirmed that these cracks formed during the earthquake.

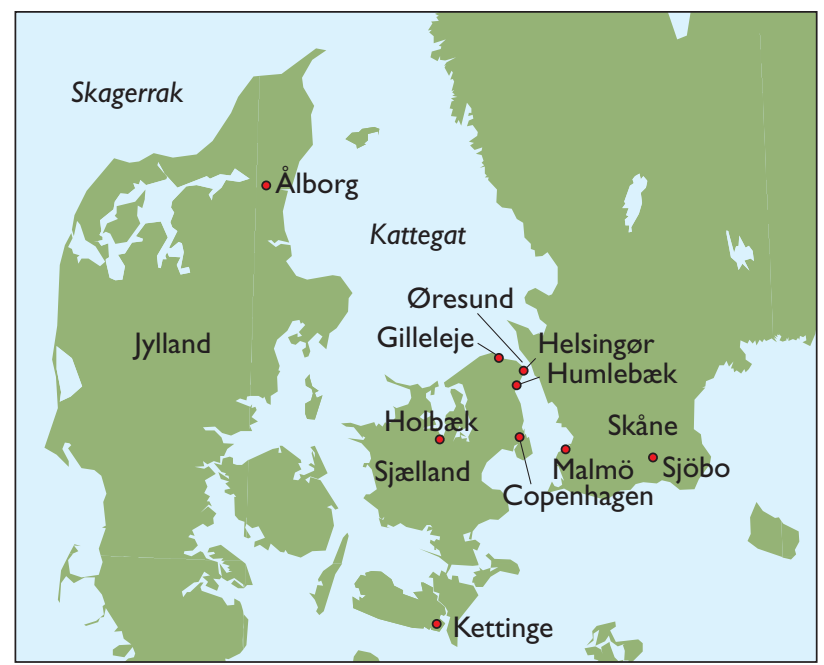

Fig. 3. Map of Denmark and south-western Sweden showing the location of place names mentioned in the text. 


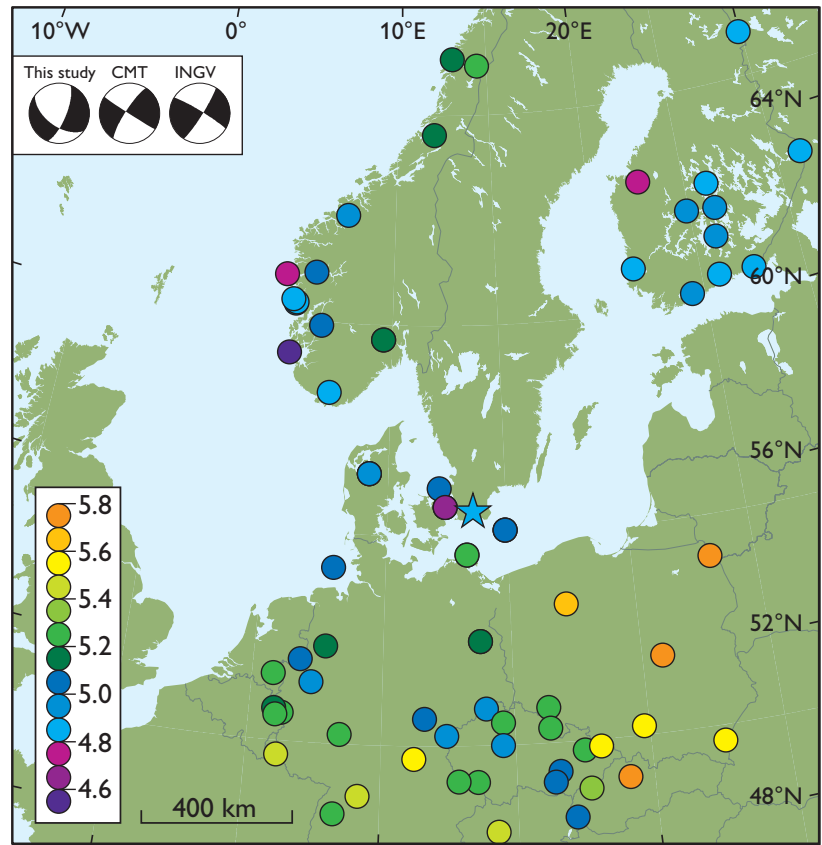

Fig. 4. Map showing magnitudes and focal mechanisms from various agencies. Each circle shows the ML estimated from the data from each seismograph. ML values are from University of Bergen, University of Helsinki, GeoForschungsZentrum in Postdam and GEUS. The 2008 epicentre is shown by a star. The focal mechanisms in the upper left corner were determined by this (preliminary) study, CMT (the global CMT project; Ekström \& Nettles 2008) and INGV (The MEDNET network; Morelli et al. 2000).

\section{Earthquake magnitude}

Determining the magnitude of an earthquake is not straightforward. Many different definitions of magnitude are in use at seismological data centres around the world. They measure fundamentally different parameters in the seismograms, all with the intention to reproduce C.F. Richter's original magnitude measure from 1935 (Richter 1935), which is in widespread use for public information and in engineering in earthquake regions. The earthquake hazards program at the United States Geological Survey (USGS) calculates up to six different magnitude values for each registered earthquake. At GEUS, two different magnitudes are calculated: our own computation of local magnitude (ML), which should give the classical Richter number (Richter 1935) for local earthquakes, and the moment magnitude (Hanks \& Kanamori 1979), which reflects the size of the fault area and the slip during the earthquake.

At GEUS, the ML is calculated from the maximum amplitude of the earthquake signal on the vertical component of the seismograph (usually the (surface) Lg wave) taking into account the distance between the earthquake and the seismograph station. When the Lg wave is observed at several seismographs, we calculate the ML as the average of the separate
ML values. It requires little data to calculate and it can be calculated shortly after the earthquake. When the data quality is low, as is often the case with weak, local earthquakes, the ML is the only magnitude that can be calculated. The calculation of ML builds on experience of how effectively the shaking propagates in the area.

The variations in the ML value calculated at different seismograph stations can be large. Following the earthquake on 16 December 2008, several European agencies reported ML values for their stations. The values ranged from 4.6 to 5.8 even though the local corrections are supposed to ensure similar values for all stations (Fig. 4). Ideally the ML values estimated at seismographs map the energy released in different directions from the earthquake, but the uncertainty in the correction of damping is large, so the pattern is only determined with some uncertainty. At GEUS, a ML value of 4.8 was calculated, identical to the ML value reported by the USGS. University of Bergen reported 4.7, University of Helsinki 4.9 and Helmholtz-Zentrum Potsdam - Deutsches GeoForschungsZentrum 5.4.

The moment magnitude is based on the seismic moment of the earthquake, a physical parameter that is proportional to the area of the fault multiplied by its slip. The moment can be determined from seismological measurements, and in special cases from geodetic measurements. A large number of clear signals on seismographs surrounding the epicentre are needed to obtain a well constrained moment magnitude, using moment tensor inversion. The moment magnitude is determined by searching for the earthquake source parameters that produce synthetic seismograms that have the best possible fit to the observed seismograms. We have determined the moment tensor and a moment magnitude of 4.2 using the method by Dreger (2003). University of Uppsala, USGS and Istituto Nazionale di Geofisica e Vulcanologia reported a moment magnitude of 4.3 .

Fault plane solutions determined in this preliminary study and by others all show a strike-slip movement with a normal component. The corresponding compressional stress field is orientated in a NNW-SSE direction as shown by the focal mechanisms (Fig. 4).

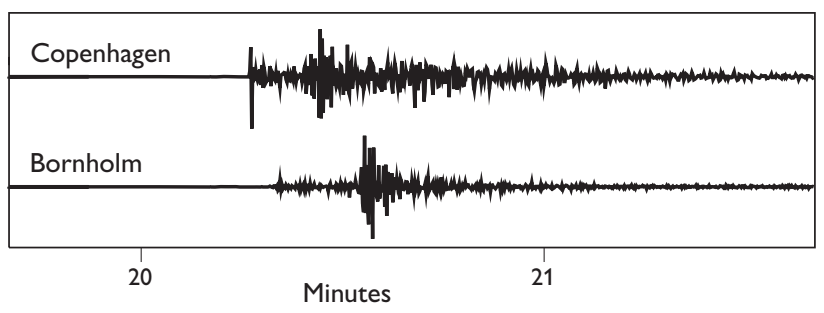

Fig. 5. Seismograms of the 16 December 2008 earthquake showing the vertical component of the broadband seismometers at Copenhagen and Bornholm, located 65 and $108 \mathrm{~km}$ from the epicentre, respectively. 


\section{Tectonic setting}

The epicentre is located in the Sorgenfrei-Tornquist Zone, which is part of a major transition zone in Europe between (1) the old Precambrian shield of Fennoscandia and eastern Europe and (2) the younger lithosphere of central Europe (Pharaoh 1999). The earthquake activity in the Sorgenfrei-Tornquist Zone is limited, with Kattegat being the most active region. The most active area in Denmark is from north-western Jylland into Skagerrak (Gregersen et al. 1998). Recent studies show that many of the earthquakes cannot be referred to known faults in the Sorgenfrei-Tornquist Zone (Gregersen et al. 1996). This is the case even though the uncertainties in the earthquake locations are large.

Faults in the top Pre-Zechstein rocks have been mapped in the area where the earthquake occurred (Fig. 1). However, the location uncertainty $(6 \mathrm{~km})$ means that one cannot link the 16 December 2008 earthquake to a known fault. This is a general problem as small earthquakes occur at depth whereas faults are mostly mapped near the surface.

A re-analysis of the data recorded by the Danish seismological network shows that no foreshocks or aftershocks were observed in the months before or after the 16 December earthquake. Seismograms of the earthquake are shown in Fig. 5.

\section{Concluding remarks}

To feel an earthquake in Denmark is rare but not unlikely. Earthquakes felt in Denmark are generally small and felt in north-western Jylland or northern Sjælland (Gregersen et al. 1998; Larsen et al. 2008). Large earthquakes with epicentres located outside Denmark have also been felt in Denmark, like the earthquakes in Lissabon in 1755, Oslo in 1904 and Kaliningrad in 2004 (Gregersen et al. 2007). The perceptibility area in Denmark of the 16 December 2008 earthquake is comparable to the perceptibility area of the Holbæk earthquake in 2001 (Larsen et al. 2008), where the earthquake was felt mostly in northern Sjælland. Also, the area is not much different from that shaking in 1930 by a small earthquake in Øresund. The shaking from the Oslo earthquake in 1904 was felt in the north-eastern part of Denmark. The Kaliningrad earthquake in 2004 was felt by many in Copenhagen and in northern Sjælland, but only marginally in the rest of Denmark.

The coincidence of the perceptibility areas must be included in future evaluations of the earthquake hazard of Denmark. Denmark is located in an area of low earthquake hazard (Giardini et al. 2003) and the danger of any damage or injury caused by an earthquake is insignificant compared to other hazards.

\section{Acknowledgements}

University of Bergen, University of Helsinki, University of Uppsala, Deutsches GeoForschungsZentrum in Postdam and USGS provided data for this study.

\section{References}

Ekström, G. \& Nettles, M. 2008: The Global CMT Project, http:// www. globalcmt.org.

Dreger, D.S. 2003: TDMT_INV: Time Domain Seismic Moment Tensor INVersion. In Lee, W.H.K., Kanamori, H., Jennings, P.C. \& Kisslinger, C. (eds): International handbook of earthquake and engineering seismology 81B, 1627 only. London: Academic Press.

Giardini, D., Jiménez, M.-J. \& Grünthal, G. (eds) 2003: EuropeanMediterranean Seismic Hazard Map. European Seismological Commission.

Gregersen, S. 1992: Crustal stress regime in Fennoscandia from focal mechanisms. Journal of Geophysical Research 97, 11,821-11,827.

Gregersen, S., Korhonen, H. \& Husebye, E.S. 1991: Fennoscandian dynamics: present-day earthquake activity. Tectonophysics 189, 333-344.

Gregersen, S., Leth, J., Lind, G. \& Lykke-Andersen, H. 1996: Earthquake activity and its relationship with geologically recent motion in Denmark. Tectonophysics 257, 265-273

Gregersen, S., Hjelme, J. \& Hjortenberg, E. 1998: Earthquakes in Denmark. Bulletin of the Geological Society of Denmark 44, 115-127.

Gregersen, S., Wiejacz, P., Debski, W., Domanski, B., Assinovskaya, B., Guterch, B., Matyniemi, P., Nikulin, V., Pacesa, A. \& Puura, V. 2007: The exceptional earthquakes in Kaliningrad District, Russia on September 21, 2004. Physics of the Earth and Planetary Interiors 164, 63-74.

Grünthal, G., Musson, R.M.W., Schwarz, J. \& Stucchi, M. (eds) 1998: European macroseismic scale 15, 99 pp. Luxembourg: Cahiers du Centre Européen de Géodynamique et de Séismologie.

Hanks, T.C., \& Kanamori, H. 1979: A moment magnitude scale. Journal of Geophysical Research 84(B5), 2348-2350.

Larsen, T.B., Gregersen, S., Voss, P.H., Bidstrup, T., \& Orozova-Bekkevold, V. 2008: The earthquake that shook central Sjælland, Denmark, November 6, 2001. Bulletin of the Geological Society of Denmark 56, 1-11.

Morelli, A., Ekström, G., Mazza, S., Pondrelli, S., Boschi, E. \& Dziewonski, A.M. 2000: Surface-wave centroid moment tensors in the Mediterranean region: the MEDNET-Harvard project. Orfeus Electronic Newsletter 2, p. 4.

Pharaoh, T. 1999: Palaeozoic terranes and their lithospheric boundaries within the Trans-European Suture Zone (TESZ): a review. Tectonophysics 314, 17-41.

Richter C.F. 1935: An instrumental earthquake magnitude scale. Bulletin of the Seismological Society of America 25, 1-32.

Scandinavian Earthquake Archive 2003: CD with scanned reports for ICG project No. 3. ICG 3-2003-3. 